\title{
PRODUÇÃO DE MUDAS DE VIDEIRA CV. BORDÔ/PAULSEN 1103 PELA ENXERTIA DE MESA COM ESTRATIFICAÇÃO
}

\author{
LARI MAROLI ${ }^{2}$, IDEMIR CITADIN ${ }^{3}$, MARCOS ROBSON SACHET $^{4}$, \\ SILVIA SCARIOTTO 5 , AMERICO WAGNER JUNIOR ${ }^{3}$
}

RESUMO - O emprego de práticas adequadas na implantação do vinhedo, principalmente o uso de mudas enxertadas com boa sanidade, é fator essencial para o sucesso da viticultura. O objetivo do trabalho foi testar temperatura de estratificação, uso do ácido indolbutírico (AIB), tipo e época de enxertia para produção de mudas da cultivar Bôrdo/Paulsen 1103 por enxertia de mesa com estratificação. No primeiro e no segundo experimentos, as estacas do porta-enxerto foram tratadas com AIB antes e após a estratificação, respectivamente. Ambos os experimentos foram conduzidos em blocos ao acaso, em esquema fatorial de $3 \times 2$ (temperaturas de estratificação: $19^{\circ} ; 24^{\circ}$ e $29^{\circ} \mathrm{C}$ x tipo enxertia: garfagem de topo e tipo Ômega), com quatro repetições, constituída por 10 unidades de observação cada. O terceiro experimento foi em blocos ao acaso, em esquema fatorial 4 x 2 (época de enxertia: maio, junho, julho e agosto x temperatura de estratificação: $19^{\circ} \mathrm{C}$ e $24^{\circ} \mathrm{C}$ ), com quatro repetições de 20 unidades de observação cada. A técnica de enxertia empregada foi de garfagem de topo, com aplicação de AIB $2.000 \mathrm{mg} \mathrm{L}^{-1}$ após a saída da estratificação. Concluiu-se que a enxertia tipo garfagem de topo apresentou melhores resultados que o tipo Ômega. Recomenda-se a aplicação de AIB após estratificação. As temperaturas de $19^{\circ} \mathrm{C}$ e $24^{\circ} \mathrm{C}$ no período de estratificação favorecem a sobrevivência em relação a $29^{\circ} \mathrm{C}$. Com a realização da enxertia em meados de julho, e a utilização da temperatura de $19^{\circ} \mathrm{C}$ na estratificação, pode-se obter elevada sobrevivência (86\%), acompanhada de melhor desenvolvimento vegetativo e radicial.

Termos para indexação: Propagação, Garfagem, Forçagem, Vitis spp.

\section{PRODUCTION OF GRAPEVINE CV. BORDÔ/PAULSEN 1103 BY BENCH GRAFTING WITH STRATIFICATION}

\begin{abstract}
The use of appropriate practices in the implementation of a vineyard, especially the use of grafted cuttings with good health, is an essential factor for successful viticulture. The objective of this study was to test stratification temperature, use of idole-butiric acid (IBA), type and period of grafting, for the propagation of vines, cultivar Bordô/Paulsen 1103, by bench grafting cuttings with stratification. In the first and second experiment, the cuttings of the rootstock were treated with IBA before and after stratification, respectively. Both treatments were conducted in a randomized block in a factorial 3 x 2 (stratification temperature: $19^{\circ}, 24^{\circ}$ and $29^{\circ} \mathrm{C}$ ) x grafting type: manual cleft grafting and "Omega"), with four replications and ten units of observation (grafted cuttings). The third experiment was performed in randomized blocks, in a 4 x 2 factorial design (different period of grafting: May, June, July, and August x stratification temperature: 19 and $24^{\circ} \mathrm{C}$ ), with four replications and 20 units of observation. The technique of grafting was manual cleft, with $2000 \mathrm{mg} \mathrm{L}^{-1}$ of IBA after stratification. Cleft grafting had a higher percentage of viable grafted cuttings than the "omega" technique; We recommend application of IBA after stratification; temperatures of 19 and $24^{\circ} \mathrm{C}$ favored the survival of the graft; while July was the most recommended period for bench grafting with stratification.
\end{abstract}

Index terms: Propagation, Cleft Grafting, Forcing technique, Vitis spp.

\footnotetext{
${ }^{1}$ (Trabalho 359-13). Recebido em:02-10-2013. Aceito para publicação em: 08-05-2014.

${ }^{2}$ Eng. Agrônomo, Mestre em Agronomia, UTFPR/PPGAG. Instituto Paranaense de Assistência Técnica e Extensão Rural - Emater. Rua Nereu Ramos, 844, 85504-320, Pato Branco. Paraná. E-mail: lari.maroli@yahoo.com.

${ }^{3}$ Eng. Agrônomo, Dr., UTFPR/PPGAG: Via do Conhecimento, Km 01, 85503-390, Pato Branco. Paraná. E-mail: idemir@utfpr.edu.br; americowagner@utfpr.edu.br.

${ }^{4}$ Eng. Agrônomo, Mestre em Agronomia, UTFPR/PPGAG. E-mail: marcos.sachet@gmail.com.

${ }^{5}$ Eng. Agrônoma, Doutoranda pela UFPel/FAEM/Agronomia/Fitomelhoramento. E-mail: silviascariotto@yahoo.com.br.
} 


\section{INTRODUÇÃO}

A viticultura brasileira surgiu com a chegada dos colonizadores portugueses, tornando-se uma atividade comercial a partir do início do século XX. Até a década de 1960, ficou limitada às regiões Sul e Sudeste (CAMARGO; TONIETTO; HOFFMANN, 2011). O Estado do Paraná é o $4^{\circ}$ maior produtor do Brasil, e em sua região sudoeste, predomina a atividade em pequenas propriedades, com $44 \%$ dos vinhedos constituídos pela cultivar Bordô, e destes, $35 \%$ são formados a partir de estacas enraizadas sem uso de porta-enxerto, tratadas também como mudas de pé-franco (ZARTH, 2011). Essa situação representa um entrave que limita a expansão da cultura, uma vez que plantas de pé-franco são em geral menos produtivas (SATISHA et al., 2010), com maior incidência de fungos associados ao declínio e à morte da planta (GARRIDO et al., 2004), além de apresentar maior suscetibilidade à pérola-da-terra (BROETTO et al., 2011).

Mudas de alta qualidade podem ser produzidas pela enxertia de mesa, em apenas um único ciclo. No Brasil, essa técnica é recente, adotada comercialmente a partir dos anos 2000 , sendo produzido anualmente, aproximadamente, 1,5 milhões de mudas (REGINA et al., 2012), quantidade considerada muito pequena se comparada com países europeus, como a França, que produz 270 milhões (REGINA, 2002).

Todavia, é possível verificar que o sucesso do método depende do porta-enxerto e de cultivarescopa utilizados (HAMDAN; BASHEER-SALIMIA, 2010; REGINA et al., 2012), técnica de enxertia e épocas de realização (VERMA et al., 2010), aplicação ou não de fitorreguladores (KÖSE; GÜLERYÜZ, 2006), entre outras.

O protocolo de enxertia de mesa, atualmente utilizado, foi adaptado utilizando-se de algumas fases e resultados encontrados em outros países, sem que houvesse pesquisa sob as condições locais (REGINA et al., 2012).

Neste contexto, o presente trabalho objetivou avaliar as respostas de diferentes tipos de enxertia, temperaturas no período de estratificação, uso de auxina e épocas de enxertia na produção de mudas de videira cultivar Bordô sob porta-enxerto Paulsen 1103.

\section{MATERIAL E MÉTODOS}

Os trabalhos foram desenvolvidos nas dependências da Universidade Tecnológica Federal do Paraná - UTFPR, Câmpus Pato Branco, durante outono/inverno, para instalação dos experimentos, e durante a primavera, para realização das avaliações, dos anos de 2010 e 2011, em condições controladas.

Para os três experimentos realizados, foram coletadas estacas de plantas-matrizes de videira (Vitis sp.), do porta-enxerto Paulsen 1103 e gemas da cultivar-copa (Bordô) com adequado estado sanitário e desprovidas de folhagem. Após, foi realizada a desinfestação, mergulhando-se o material vegetal por 10 minutos, em solução de hipoclorito de sódio (1\%), enxaguando-as em água corrente (3 vezes), seguido da borrifação com solução de álcool a 70\%.

Em seguida, as estacas do porta-enxerto foram cortadas em tamanho de 25 a $30 \mathrm{~cm}$, o corte inferior foi a $1 \mathrm{~cm}$ abaixo do primeiro nó e o corte superior a $3 \mathrm{~cm}$ acima do último nó. Todas as gemas do porta-enxerto foram retiradas para evitar sua brotação. As gemas da variedade copa foram selecionadas e cortadas, mantendo-se $3 \mathrm{~cm}$ acima e abaixo da gema para facilitar o processo de enxertia.

$\mathrm{O}$ primeiro experimento foi realizado em meados de julho de 2010, no qual foram testados diferentes temperaturas de estratificação e diferentes tipos de enxertia. O delineamento experimental foi em blocos ao acaso, segundo esquema fatorial $3 \times 2$ (19; 24 e $29^{\circ} \mathrm{C}$ x enxertia garfagem e tipo Ômega), com quatro repetições de 10 enxertos por unidade experimental. Foi utilizado, na base das estacas, ácido 4,3-indolilbutírico (AIB) na concentração $2.000 \mathrm{mg} \mathrm{L}^{-1}$ após a saída da estratificação, mergulhando-se a base das mesmas por 5 segundos nesta solução. Para melhorar a absorção do AIB, foi realizada incisão na base da estaca.

O segundo experimento seguiu as mesmas descrições realizadas no experimento anterior, porém o tratamento com AIB $2.000 \mathrm{mg} \mathrm{L}^{-1}$ foi realizado antes da entrada na estratificação, logo após a realização da enxertia.

$\mathrm{O}$ terceiro experimento foi implantado no ano de 2011, o delineamento experimental utilizado foi em blocos ao acaso, em esquema fatorial de $4 \times 2$ (época de enxertia x temperatura de estratificação), com quatro repetições de 20 enxertos por unidade experimental. $\mathrm{O}$ fator época de enxertia foi maio, junho, julho e agosto, e o fator da temperatura de estratificação foi $19^{\circ} \mathrm{C}$ e $24^{\circ} \mathrm{C}$. A técnica de enxertia empregada foi de garfagem de topo, no dia 15 de cada época, imediatamente após a coleta das estacas em campo e o preparo das mesmas conforme descrito acima. A aplicação de AIB $2.000 \mathrm{mg} \mathrm{L}^{-1}$ foi realizada após a saída da estratificação.

As estacas enxertadas foram envolvidas em jornal, para permanecerem no escuro, colocadas em vasos com água, sendo que o nível da água não excedeu $1 / 3$ da altura da estaca e mantidas em BOD 
por 21 dias, com temperatura controlada de acordo com o tratamento.

Aos 21 DAE (dias após enxertia), as estacas foram retiradas da estratificação. Avaliou-se a formação de calo visível na região da enxertia e a presença de brotação. Em seguida, cada enxerto foi plantado em vaso, com capacidade aproximada de 3 L, contendo substrato comercial Humusfértil ${ }^{\circledR}$. Os enxertos nos vasos foram mantidos em casa de vegetação com controle de temperaturas mínimas e máximas $\left(15^{\circ} \mathrm{C}\right.$ a $\left.30^{\circ} \mathrm{C}\right)$ e irrigação manual diária.

Após 120 dias em casa de vegetação (141 DAE), foram avaliados o percentual de sobrevivência dos enxertos, o comprimento da brotação, o comprimento médio das três maiores raízes e o número de raízes adventícias ligadas à estaca. Determinaram-se também a área foliar de cada planta em medidor de área (LI-COR 3100), a massa da matéria seca das raízes e a parte aérea da brotação, após secagem em estufa a $60^{\circ} \mathrm{C}$ até massa constante. Calculou-se a somatérmica em graus-dia (GD) durante o crescimento em casa de vegetação por 120 dias, em temperaturas coletadas com auxílio de datalogger. O cálculo dos graus-dias foi obtido pela seguinte equação $\mathrm{GD}=\sum(\mathrm{Th}-\mathrm{Tb}) / 24$, em que: Th é a temperatura horária e $\mathrm{Tb}$ a temperatura-base de $10{ }^{\circ} \mathrm{C}$.

Os dados foram analisados quanto a sua homogeneidade de variâncias dos erros pelo teste de Bartlett e normalidade por Lilliefors. Os conjuntos cujas variâncias se mostraram homogêneas e normais foram submetidos à análise de variância (ANOVA). Quando o resultado do teste $\mathrm{F}$ indicou diferença significativa $(p \leq 0,05)$, as médias foram comparadas pelo teste de Tukey $(p=0,05)$. As variáveis do Experimento II foram submetidas às seguintes transformações: sobrevivência $\left(\log _{10} \mathrm{X}+1\right)$, comprimento de raízes e número de raízes (arcosen $\mathrm{X} / 100$ ), para posterior análise de variância e teste de médias. As análises estatísticas foram realizadas pelo programa Genes (CRUZ, 2006).

\section{RESULTADOS E DISCUSSÃO}

O percentual de calo visível variou de $0,0 \%$ a $97,5 \%$, sendo os maiores percentuais obtidos pelo efeito da enxertia tipo Ômega e aumento da temperatura de estratificação. Köse e Güleryüz (2006) obtiveram de 7 a 18\% de calo em Ômega, após 21 dias de estratificação à $24^{\circ} \mathrm{C}$, com sobrevivência de 0 a $10 \%$. Valores próximos foram obtidos neste experimento em Ômega $+24^{\circ} \mathrm{C}$ para formação de calo $(30 \%)$ e sobrevivência $(12,5 \%)$ (Tabela 1$)$.
A formação de calo pode variar com método de enxertia e interação entre cultivar-copa e portaenxerto (KORKUTAL et al., 2011) e entre épocas de realização da enxertia (ÇELİK, 2000). Köse e Güleryüz (2006) observaram correlação negativa $(-0,66)$ entre formação de calo e enraizamento, indicando a possível competição entre calogênese e rizogênese. Os tratamentos a 24 e $29^{\circ} \mathrm{C}$, nesse experimento, apresentavam excessiva formação de calo de cor branca e friável, presente por toda a extensão do encaixe, o que influenciou de forma negativa sobre o posterior desempenho das mudas.

Para percentual de brotação, os valores variaram de $0 \%$ a $100 \%$, com maiores médias nos tratamentos com aplicação de auxina antes da estratificação, utilizando-se da enxertia tipo garfagem de topo e temperatura de $29^{\circ} \mathrm{C}$ (Tabela 1). A brotação precoce não é desejada, sendo uma fonte de dreno, pois esta ocorre concomitantemente com outros eventos importantes, como a formação de tecidos e vasos condutores.

O percentual de sobrevivência variou de $0 \%$ a $75 \%$. Não houve diferença significativa entre os tratamentos com o uso de AIB antes da estratificação. $\mathrm{Na}$ aplicação de AIB após a estratificação, houve superioridade da enxertia tipo garfagem em relação ao Ômega e incremento da sobrevivência com redução da temperatura (Tabela 1).

As variáveis comprimento de brotação $(\mathrm{CB})$ e de raízes (CR), matéria seca de raízes (MSR) e da brotação (MSB), área foliar (AF) e número de raízes (NR) dos tratamentos com aplicação de AIB antes da estratificação não diferiram (Tabela 2). Na aplicação de AIB após a estratificação, os tratamentos que apresentaram sobrevivência foram superiores e não diferiram entre si, exceto para MSR em garfagem $+19^{\circ} \mathrm{C}(6,0 \mathrm{~g})$, que foi inferior a Ômega $+19^{\circ} \mathrm{C}(7,3 \mathrm{~g})$, sem comprometer o vigor das mudas. Em ambos os experimentos, foi possível constatar que, após estabelecida a sobrevivência das mudas, há pouco ou nenhum efeito dos tratamentos sobre o seu desenvolvimento. Assim, pode-se recomendar para uso o tratamento que apresentou maior sobrevivência, refletindo a maior eficiência de produção de mudas. Contudo, Sabir (2011) e Korkutal et al. (2011) relatam que o desenvolvimento vegetativo da cultivar-copa é altamente dependente do método de enxertia, da formação de calo e da união de ambos. Esta união é que vai garantir a transmissão adequada de nutrientes e produtos da fotossíntese entre porta-enxerto e cultivar-copa. $\mathrm{Ou}$ seja, os resultados obtidos neste trabalho poderão não se repetir para outras variedades de videira, caso não ocorra boa compatibilidade entre o porta-enxerto e 
a cultivar-copa.

Em face dos resultados obtidos em 2010, com superioridade da enxertia de garfagem + aplicação de AIB após a estratificação em temperaturas de $19^{\circ} \mathrm{C}\left(75 \%\right.$ de sobrevivência) ou $24^{\circ} \mathrm{C}(67,5 \%$ de sobrevivência), optou-se por aplicá-los em diferentes épocas, no período de dormência (maio, junho, julho e agosto), visando a determinar a melhor época de coleta de estacas e realização da enxertia.

Observou-se interação entre épocas de enxertia e temperaturas para a variável sobrevivência (SOB). Para as demais variáveis, houve efeito significativo apenas para épocas de enxertia (Tabela 3).

Quanto à SOB, os valores observados variaram de 50 a 95\%, sendo valores iguais ou superiores ao preconizado para a enxertia de mesa (REGINA et al., 2012). Não se identificaram diferenças significativas entre as épocas para a temperatura de estratificação de $19^{\circ} \mathrm{C}$, sendo seus valores variando de $66 \%$ (agosto) a 86\% (julho). Sob temperatura de $24^{\circ} \mathrm{C}$, junho e agosto apresentaram os menores percentuais de sobrevivência, respectivamente, com valores de $52,5 \%$ e $50 \%$. Se consideradas as variáveis em conjunto, as quatro épocas de enxertia para temperatura de estratificação de $19^{\circ} \mathrm{C}$ e as épocas de maio e julho para temperatura de $24^{\circ} \mathrm{C}$ não diferiram entre si e apresentam os melhores resultados na sobrevivência de enxertos (Tabela 3).

Segundo a dinâmica da dormência de videira em região de baixo acúmulo de frio (BIASI et al., 2010), é possível que em junho o material vegetal se encontrasse com a maior profundidade de endodormência, nessa situação, e a baixa atividade metabólica influenciou na redução de sobrevivência nessa época, principalmente a $24^{\circ} \mathrm{C}$. Em agosto, as gemas já haviam superado a endodormência e necessitavam apenas acumular calor para brotar, e, ao ser levada para estratificação, a brotação ocorreu precocemente, o que ocasionou novamente redução de sobrevivência. Assim, a época que antecedeu (maio) e a que precedeu (julho) a maior profundidade de endodormência foram as que apresentaram maiores sobrevivências.

Por se tratar de épocas distintas, as estacas ficaram expostas 120 dias em casa de vegetação sob diferentes somas térmicas (graus-dia, GD); com isso, as mudas desenvolveram-se sob 1.081 GD no tratamento de maio, 1.286 GD no de junho, 1.418 GD no de julho e 1.581 GD no de agosto. O incremento na soma térmica ao avançar as épocas foi seguido por brotações maiores (CB), com maior acúmulo de matéria seca da brotação (MSB) e área foliar (AF), raízes maiores (CR), com maior acúmulo de matéria seca radicular (MSR), enquanto, para número de raízes (NR), houve tendência de redução (exceto em julho). O mês de junho apresentou os menores valores de desempenho das mudas, isso é atribuído ao retardamento da brotação e erratismo de crescimento comumente observado em plantas de clima temperado estratificados no pico de endodormência, como também, pela menor soma térmica, se comparado com julho e agosto. O mês de julho apresentou melhor combinação entre sobrevivência (79,3\%), desenvolvimento vegetativo e radicial, enquanto, em maio, a maior sobrevivência $(88,7 \%)$ é gerada por mudas com menor desempenho. 
TABELA 1- Médias de formação de calo e brotação aos 21 dias após enxertia (DAE) e sobrevivência aos 141 DAE, para tratamentos em diferentes enxertias e temperaturas, no período de estratificação, nos experimentos com aplicação de AIB antes ou após a estratificação. UTFPR, Câmpus Pato Branco, 2013.

\begin{tabular}{|c|c|c|c|}
\hline \multirow{2}{*}{ Tratamentos } & \multicolumn{2}{|c|}{$21 \mathrm{DAE}$} & \multirow{2}{*}{$\begin{array}{c}141 \text { DAE } \\
\text { Sobrevivência (\%) }\end{array}$} \\
\hline & Calo (\%) & Brotação (\%) & \\
\hline \multicolumn{4}{|c|}{ AIB antes da estratificação } \\
\hline Ômega $+19^{\circ} \mathrm{C}$ & $2,5 \mathrm{Ab}$ & 62,5 ns & $30,0 \mathrm{~ns}$ \\
\hline garfagem $+19^{\circ} \mathrm{C}$ & $0,0 \mathrm{Ac}$ & 42,5 & 55,0 \\
\hline Ômega $+24^{\circ} \mathrm{C}$ & $13,3 \mathrm{Bb}$ & 17,5 & 12,5 \\
\hline garfagem $+24^{\circ} \mathrm{C}$ & $30,0 \mathrm{Ab}$ & 0,0 & 32,5 \\
\hline Ômega $+29^{\circ} \mathrm{C}$ & $77,5 \mathrm{Ba}$ & 77,5 & 27,5 \\
\hline garfagem $+29^{\circ} \mathrm{C}$ & $97,5 \mathrm{Aa}$ & 80,0 & 15,0 \\
\hline \multicolumn{4}{|l|}{ Médias } \\
\hline $19^{\circ} \mathrm{C}$ & - & $52,5 \mathrm{~A}$ & $42,5^{\mathrm{ns}}$ \\
\hline $24^{\circ} \mathrm{C}$ & - & $8,7 \mathrm{~B}$ & 22,5 \\
\hline $29^{\circ} \mathrm{C}$ & - & $78,7 \mathrm{~A}$ & 21,25 \\
\hline $\mathrm{CV}(\%)$ & 22,5 & 34,9 & 56,9 \\
\hline \multicolumn{4}{|l|}{ AIB após estratificação } \\
\hline Ômega $+19^{\circ} \mathrm{C}$ & $10,0 \mathrm{Ab}$ & $22,5 \mathrm{~ns}$ & $30,0 \mathrm{Ba}$ \\
\hline garfagem $+19^{\circ} \mathrm{C}$ & $0,0 \mathrm{Ab}$ & 10,0 & $75,0 \mathrm{Aa}$ \\
\hline Ômega $+24^{\circ} \mathrm{C}$ & $20,0 \mathrm{Aab}$ & 7,5 & $0,0 \mathrm{Bb}$ \\
\hline garfagem $+24^{\circ} \mathrm{C}$ & $5,0 \mathrm{Ab}$ & 2,5 & $67,5 \mathrm{Aa}$ \\
\hline Ômega $+29^{\circ} \mathrm{C}$ & $42,5 \mathrm{Ba}$ & 100,0 & $0,0 \mathrm{Ab}$ \\
\hline garfagem $+29^{\circ} \mathrm{C}$ & $75,0 \mathrm{Aa}$ & 70,0 & $0,0 \mathrm{Ab}$ \\
\hline \multicolumn{4}{|l|}{ Médias } \\
\hline $19^{\circ} \mathrm{C}$ & - & $16,3 \mathrm{~B}$ & - \\
\hline $24^{\circ} \mathrm{C}$ & - & $2,5 \mathrm{~B}$ & - \\
\hline $29^{\circ} \mathrm{C}$ & - & $85,0 \mathrm{~A}$ & - \\
\hline $\mathrm{CV}(\%)$ & 64,1 & 30,6 & 10,5 \\
\hline
\end{tabular}

Médias seguidas por letras distintas, maiúsculas, diferem entre si para método de enxertia em cada temperatura, e minúsculas para temperatura de estratificação dentro de cada método de enxertia, pelo teste de Tukey $(p=0,05)$. ${ }^{\text {ns }}$ Não significativo $(p>0,05)$ pelo teste $\mathrm{F}$. 
TABELA 2- Médias de comprimento de brotação (CB) e de raízes (CR), massa seca do sistema radicular (MSR) e da brotação (MSB), área foliar (AF) e número de raízes aos 141 DAE. UTFPR, Câmpus Pato Branco, 2013.

\begin{tabular}{ccccccc}
\hline \multirow{2}{*}{ Tratamentos } & \multicolumn{5}{c}{ Variáveis aos 141 DAE } \\
\cline { 2 - 7 } & $\mathrm{CB}(\mathrm{cm})$ & $\mathrm{CR}(\mathrm{cm})$ & MSR $(\mathrm{g})$ & $\mathrm{MSB}(\mathrm{g})$ & $\mathrm{AF}\left(\mathrm{cm}^{2}\right)$ & $\mathrm{NR}$ \\
\hline \multirow{5}{*}{ OIB antes da estratificação } \\
Ômega $+19^{\circ} \mathrm{C}$ & $47,3 \mathrm{~ns}$ & $50,2^{\mathrm{ns}}$ & $3,5^{\mathrm{ns}}$ & $6,0 \mathrm{~ns}$ & $924^{\mathrm{ns}}$ & $16,0 \mathrm{~ns}$ \\
garfagem $+19^{\circ} \mathrm{C}$ & 58,4 & 54,6 & 4,6 & 7,1 & 1151 & 25,7 \\
Ômega $+24^{\circ} \mathrm{C}$ & 56,4 & 47,7 & 5,4 & 8,5 & 1291 & 15,8 \\
garfagem $+24^{\circ} \mathrm{C}$ & 57,3 & 53,1 & 4,4 & 7,2 & 1055 & 25,8 \\
OOmega $+29^{\circ} \mathrm{C}$ & 51,7 & 53,2 & 4,8 & 5,5 & 956 & 21,5 \\
garfagem $+29^{\circ} \mathrm{C}$ & 34,7 & 49,9 & 2,2 & 4,8 & 825 & 13,8 \\
$\mathrm{CV}(\%)$ & 26,9 & 4,8 & 52,7 & 38,1 & 31,5 & 37,8 \\
\hline & & $\mathrm{AIB}$ após a estratificação & & \\
Ômega $+19^{\circ} \mathrm{C}$ & $40,6 \mathrm{Aa}$ & $41,0 \mathrm{Aa}$ & $7,3 \mathrm{Aa}$ & $7,7 \mathrm{Aa}$ & $912 \mathrm{Aa}$ & $24,6 \mathrm{Aa}$ \\
garfagem $+19^{\circ} \mathrm{C}$ & $35,3 \mathrm{Aa}$ & $39,8 \mathrm{Aa}$ & $6,0 \mathrm{Ba}$ & $7,3 \mathrm{Aa}$ & $907 \mathrm{Aa}$ & $24,5 \mathrm{Aa}$ \\
Ômega $+24^{\circ} \mathrm{C}$ & $0,0 \mathrm{Bb}$ & $0,0 \mathrm{Bb}$ & $0,0 \mathrm{Bb}$ & $0,0 \mathrm{Bb}$ & $0,0 \mathrm{Bb}$ & $0,0 \mathrm{Bb}$ \\
garfagem $+24^{\circ} \mathrm{C}$ & $39,9 \mathrm{Aa}$ & $41,2 \mathrm{Aa}$ & $6,5 \mathrm{Aa}$ & $8,0 \mathrm{Aa}$ & $994 \mathrm{Aa}$ & $27,3 \mathrm{Aa}$ \\
Ômega $+29^{\circ} \mathrm{C}$ & $0,0 \mathrm{Ab}$ & $0,0 \mathrm{Ab}$ & $0,0 \mathrm{Ab}$ & $0,0 \mathrm{Ab}$ & $0,0 \mathrm{Ab}$ & $0,0 \mathrm{Ab}$ \\
garfagem $+29^{\circ} \mathrm{C}$ & $0,0 \mathrm{Ab}$ & $0,0 \mathrm{Ab}$ & $0,0 \mathrm{Ab}$ & $0,0 \mathrm{Ab}$ & $0,0 \mathrm{Ab}$ & $0,0 \mathrm{Ab}$ \\
$\mathrm{CV}(\%)$ & 25,9 & 15,8 & 20,4 & 32,1 & 25,0 & 12,1 \\
\hline
\end{tabular}

Médias seguidas por letras distintas, maiúsculas, diferem entre si para método de enxertia em cada temperatura, e minúscula para temperatura de estratificação dentro de cada método de enxertia, pelo teste de Tukey $(p=0,05)$. ${ }^{\text {ns }}$ Não significativo $(p>0,05)$ pelo teste $\mathrm{F}$.

TABELA 3- Médias de sobrevivência (SOB), comprimento de brotação (CB) e de raízes (CR), massa seca do sistema radicular a diferentes épocas de enxertia e temperaturas de estratificação. UTFPR, Câmpus Pato Branco, 2013.

\begin{tabular}{|c|c|c|c|c|c|c|c|c|}
\hline \multicolumn{2}{|c|}{ Tratamentos } & \multicolumn{7}{|c|}{$141 \mathrm{DAE}$} \\
\hline Meses & Temperaturas & SOB $(\%)$ & $\mathrm{CB}(\mathrm{cm})$ & $\mathrm{CR}(\mathrm{cm})$ & $\operatorname{MSR}(\mathrm{g})$ & $\operatorname{MSB}(\mathrm{g})$ & $\mathrm{AF}\left(\mathrm{cm}^{2}\right)$ & NR \\
\hline \multirow{2}{*}{ Maio } & $19^{\circ} \mathrm{C}$ & $82,5 \mathrm{Aa}$ & $31,0 \mathrm{~ns}$ & $32,2 \mathrm{~ns}$ & $2,4^{\mathrm{ns}}$ & $3,6^{\mathrm{ns}}$ & $577 \mathrm{~ns}$ & $28,4^{\mathrm{ns}}$ \\
\hline & $24^{\circ} \mathrm{C}$ & $95,0 \mathrm{Aa}$ & 34,2 & 33,9 & 3,2 & 3,9 & 620 & 29,8 \\
\hline \multirow{2}{*}{ Junho } & $19^{\circ} \mathrm{C}$ & $76,2 \mathrm{Aa}$ & 17,7 & 38,7 & 2,4 & 2,5 & 351 & 26,3 \\
\hline & $24^{\circ} \mathrm{C}$ & $52,5 \mathrm{BCb}$ & 16,8 & 42,0 & 2,9 & 2,7 & 410 & 22,9 \\
\hline \multirow{2}{*}{ Julho } & $19^{\circ} \mathrm{C}$ & $86,2 \mathrm{Aa}$ & 43,3 & 48,0 & 4,7 & 6,7 & 744 & 40,1 \\
\hline & $24^{\circ} \mathrm{C}$ & $72,5 \mathrm{Ba}$ & 39,9 & 47,7 & 4,7 & 7,8 & 900 & 33,1 \\
\hline \multirow{2}{*}{ Agosto } & $19^{\circ} \mathrm{C}$ & $66,2 \mathrm{Aa}$ & 37,5 & 50,7 & 3,4 & 4,8 & 670 & 25,3 \\
\hline & $24^{\circ} \mathrm{C}$ & $50,0 \mathrm{Ca}$ & 36,8 & 54,4 & 3,7 & 5,2 & 750 & 22,6 \\
\hline \multicolumn{9}{|c|}{ Médias para meses } \\
\hline \multicolumn{2}{|c|}{ Maio (1081 GD) } & $88,7^{z}$ & $32,6 \mathrm{~A}$ & $33,0 \mathrm{C}$ & $2,80 \mathrm{~B}$ & $3,7 \mathrm{~B}$ & $599 \mathrm{AB}$ & $29,1 \mathrm{~B}$ \\
\hline \multicolumn{2}{|c|}{ Junho (1286 GD) } & 64,3 & $17,3 \mathrm{~B}$ & $40,3 \mathrm{BC}$ & $2,61 \mathrm{~B}$ & $2,6 \mathrm{~B}$ & $380 \mathrm{~B}$ & $24,6 \mathrm{C}$ \\
\hline \multicolumn{2}{|c|}{ Julho (1418 GD) } & 79,3 & $41,6 \mathrm{~A}$ & $47,9 \mathrm{AB}$ & $4,72 \mathrm{~A}$ & $7,3 \mathrm{~A}$ & $822 \mathrm{~A}$ & $36,6 \mathrm{~A}$ \\
\hline \multicolumn{2}{|c|}{ Agosto (1581 GD) } & 58,1 & $37,2 \mathrm{~A}$ & $52,6 \mathrm{~A}$ & $3,54 \mathrm{AB}$ & $5,0 \mathrm{AB}$ & $710 \mathrm{~A}$ & $23,9 \mathrm{D}$ \\
\hline \multicolumn{9}{|c|}{ Médias para temperaturas } \\
\hline \multicolumn{2}{|c|}{$19^{\circ} \mathrm{C}$} & $77,8^{z}$ & $32,4^{\text {ns }}$ & $42,4^{\text {ns }}$ & $3,21^{\text {ns }}$ & $4,4^{\mathrm{ns}}$ & $586^{\mathrm{ns}}$ & $30,0^{\mathrm{ns}}$ \\
\hline \multicolumn{2}{|c|}{$24^{\circ} \mathrm{C}$} & 67,5 & 31,9 & 44,5 & 3,62 & 4,9 & 670 & 27,1 \\
\hline \multicolumn{2}{|c|}{ CV $(\%)$} & 13,38 & 19,68 & 9,85 & 24,76 & 28,08 & 22,2 & 13,15 \\
\hline
\end{tabular}

Médias seguidas por letras distintas, maiúsculas para meses e minúsculas para temperaturas, diferem entre si, pelo teste de Tukey ( $p$ $=0,05) \cdot{ }^{\mathrm{z}}$ Considerar a interação. ${ }^{\text {ns }}$ Não significativo $(p>0,05)$ pelo teste $\mathrm{F}$. 


\section{CONCLUSÕES}

Nas condições em que o trabalho foi executado, pode-se concluir que:

- a enxertia tipo garfagem de topo apresenta melhores resultados que o tipo Ômega.

- recomenda-se a aplicação de AIB $(2.000 \mathrm{mg}$

$\left.\mathrm{L}^{-1}\right)$ após estratificação;

- as temperaturas de $19^{\circ} \mathrm{C}$ e $24^{\circ} \mathrm{C}$, no período de estratificação, favorecem a sobrevivência em relação a $29^{\circ} \mathrm{C}$.

- o mês de julho é o mais recomendado para coleta de estacas e realização da enxertia de mesa com estratificação da cultivar Bordô sobre o portaenxerto Paulsen 1103.

\section{REFERÊNCIAS}

BIASI, L.A.; CARVALHO, R.I.N. de; ZANETTE, F. Dinâmica da dormência de gemas de videira e quivizeiro em região de baixa ocorrência de frio. Revista Brasileira de Fruticultura, Jaboticabal, v.32, n.4, p.1244-1.249, 2010.

BROETTO, D.; BAUMANN JÚNIOR, D.; SATO, A.J.; BOTELHO, R.V. Desenvolvimento e ocorrência de pérola-da-terra em videiras rústicas e finas enxertadas sobre os porta-enxertos 'VR 043-43' e 'Paulsen 1103'. Revista Brasileira de Fruticultura, Jaboticabal, Volume especial, p.404-410, Outubro 2011.

CAMARGO, U.A.; TONIETTO, J.; HOFFMANN, A. Progressos na viticultura brasileira. Revista Brasileira de Fruticultura, Jaboticabal,Volume especial, p.144-149, Outubro 2011.

ÇELIK, H. The effects of different grafting methods applied by manual grafting units. Turkish Journal of Agriculture and Forestry, Ankara, v.24, p.499504, 2000.

Cruz, C.D. Programa Genes: Biometria. Editora UFV. Viçosa-MG. 382p. 2006

GARRIDO, L.D.R.; SÔNEGO, O.R.; GOMES, V.N. Fungos associados com o declínio e morte de videiras no Estado do Rio Grande do Sul. Fitopatologia Brasileira, Brasília, v.29, n.3, p.322-324, 2004.
HAMDAN, A-J.S.; BASHEER-SALIMIA, R. Preliminary compatibility between some tablegrapevine scion and phylloxera-resistant rootstock cultivars. Jordan Journal of Agricultural Sciences, Amman, v.6, n.1, p.1-10, 2010.

KORKUTAL, I.; KAYGUSUZ, G.; BAYRAM, S. Different effect of scion types on callusing in bench grafting. African Journal of Biotechnology, Nairobi, v.10, n.67, p.15.123-15.129, 2011.

KÖSE, C.; GÜLERYÜZ, M. Effects of auxins and cytokinins on graft union of grapevine (Vitis vinifera). New Zealand Journal of Crop and Horticultural Science, Wellington, v.34, n.2, p.145-150, 2006.

REGINA, M. de A. Produção e certificação de mudas de videira na França 1. Situação atual da produção. Revista Brasileira de Fruticultura, Jaboticabal, v.24, n.2, p.586-589, 2002.

REGINA, M. de A.; SOUZA, C.R. de; DIAS, F.A.N. Propagação de Vitis spp. pela enxertia de mesa utilizando diferentes porta-enxertos e auxinas.

Revista Brasileira de Fruticultura, Jaboticabal, v.34, n.3, p.897-904, 2012.

SABIR, A. Comparison of green grafting techniques for success and vegetative development of grafted grape cultivars (Vitis spp.). International Journal of Agriculture and Biology, Faisalabad, v.13, n.4, p. $628-630,2011$.

SATISHA, J.; SOMKUWAR, R.G.; SHARMA, J.; UPADHYAY, A.K.; ADSULE, P.G. Influence of rootstocks on growth yield and fruit composition of Thompson Seedless grapes grown in the Pune Region of India. South African Journal for Enology and Viticulture, Stellenbosch,v.31, n.3, p.1-8, 2010.

VERMA, S. K.; SINGH S.K.; PATEL, V.B.; SINGH, K.M. Grafting and stionic effect studies in grape. Journal of Rural and Agricultural Research, Agra, v.10, n.1, p.01-03, 2010.

ZARTH, N. A. Caracterização e análise da cadeia da vitivinicultura no Sudoeste do Paraná. 2011. 130f. Dissertação (Mestrado em Agronomia) Universidade Tecnológica Federal do Paraná, Pato Branco, 2011. 